\title{
GUATEMALA: \\ CONFLICTOS CAMPESINOS \\ Y DESARROLLO RURAL, 1993-1994
}

\section{Julio Castellanos Cambranes*}

$\mathrm{P}$

ese a ser Guatemala un país predominantemente rural, cuya historia ha estado plagada de conflictos campesinos, las luchas sociales en el campo han sido un fenómeno muy poco investigado. Los conflictos campesinos de los últimos tiempos, estrechamente relacionados a la estructura de la propiedad de la tierra, a la explotación de los trabajadores rurales y al sistema de dominación social de los finqueros, tampoco han sido debidamente estudiados por los científicos sociales en general, y por los sociólogos en particular. Parafraseando a un conocido político internacional, nunca tan grandes problemas interesaron a tan pocos. A lo sumo, el hecho histórico y político-social que más ha despertado el interés de los académicos ha sido el agrarismo desatado en Guatemala de 1951 a 1954, durante el Gobierno de Jacobo Arbenz. Fue el período en que los campesinos se volvieron revolucionarios. Entonces, alentados por la promulgación del Decreto 900 de Reforma Agraria, decidieron hacerle frente a sus explotadores, tomaron la iniciativa, y en casi todas las regiones del país se apoderaron de las fincas donde habían laborado por generaciones.'

El violento estallido del conflicto campesino en Chiapas, en enero del 94, ampliamente divulgado por la prensa mundial, ha conducido ya a que numerosos analistas políticos, sociólogos, y hasta

- Profesor de la Universidad Autónoma de Madrid 
literatos, estén produciendo un cada vez mayor número de estudios y ensayos académicos sobre el tema de la agitación campesina en el sur de México. El resultado es que todo el mundo, literalmente, está ya enterado de que en México existe un Estado llamado Chiapas, donde un tal "subcomandante Marcos» dirige un movimiento armado campesino que exige una reforma agraria. De la vecina Guatemala, por el contrario, de la cual se ha dicho que sólo está separada geográficamente de Chiapas por un río que no tiene agua, la prensa mundial rara vez publica algo acerca del conflicto armado campesino que tiene ya más de treinta años de existencia y de que ha tenido en jaque a más de uno de los diversos gobiernos militares que se han sucedido en el poder.

Lo que es aún peor, en la misma Guatemala se ignora casi todo lo relacionado con las causas y el desarrollo de este movimiento campesino insurgente que ha costado ya cerca de 200,000 muertes. No tengo conocimiento de que algún científico social se haya tomado la molestia de hacer un estudio y análisis serio, en donde se ponga en evidencia que este conflicto campesino - que a menudo se nos pretende presentar como un movimiento guerrillero integrado por un puñado de desesperados-, ha sido el efecto directo de la contrarrevolución de 1954, que dió al traste con la Reforma Agraria de Arbenz.

Como es sabido, la anulación del Decreto 900 dejó en el medio rural una conflictividad potencial, al devolvérseles a los finqueros las tierras que les habían sido expropiadas por la Reforma Agraria, y retornarse al antiguo e injusto sistema de desigual distribución de la propiedad de la tierra que se creía superado. El detonante del movimiento insurgente campesino fue la acción armada de militares rebeldes patriotas, quienes, con la ayuda de jóvenes revolucionarios intentaron, a partir de 1962, repetir en Guatemala la acción de los revolucionarios cubanos que establecieron el Primer Territorio Libre de América.

Por consiguiente, el conflicto armado campesino guatemalteco está vinculado a la frustrada revolución democrático burguesa de 1944-54, a su malograda Reforma Agraria, y ha sido una respuesta a la contrarrevolución de 1954. Las raíces del conflicto insurgente y de las agitaciones campesinas que existen hoy en día en Guatemala, sin embargo, $-y$ ésto no hay que cansarse de repetirlo y señalarlo siempre con suficiente claridad-, se encuentran en la 
miseria imperante en el medio rural y en la agudización de la lucha de clases en la sociedad guatemalteca. En cualquier caso, es tiempo ya de que los científicos sociales guatemaltecos se a esclarecer el contenido reivindicativo de los conflictos campesinos que han proliferado en el país en las últimas cuatro décadas.

El motivo principal de este trabajo es contribuir al esclarecimiento de los conflictos campesinos en Guatemala, caracterizando los producidos en meses recientes, en el período en que debido a una coyuntura política ascendió a la Presidencia de la República cafetalera Ramiro de León Carpio, el ex-Procurador de los Derechos Humanos, convertido hoy en el nuevo representante de los intereses de los finqueros y de los altos jefes militares, los verdaderos gobernantes del país. Dichos conflictos campesinos han tenido diversas modalidades. Además de la mencionada lucha armada insurgente, las aspiraciones campesinas a la elevación de su miserable condición de vida han conducido a ocupaciones de fincas privadas y tierras estatales, huelgas y demandas de aumentos salariales, y, en no pocos casos, a confrontaciones directas y choques sangrientos con la policía y el ejército.

Metodológicamente, considero campesino a toda persona o conglomerado social que en el medio rural se dedica con su esfuerzo físico, individual o colectivamente, al cultivo de la tierra y a la producción agraria, independiente de que se trate de un pequeño productor privado o arrendatario, o de un trabajador rural que participa en la producción agrariá a cambio de un salario. Por consiguiente, denomino campesino tanto al minifundista y pequeño propietario, como al colono de una finca, al aparcero, al pequeno arrendatario, y al jornalero agrícola temporal y permanente. Esta definición es básica para comprender a cabalidad los conflictos rurales que analizaremos, y que se derivan, en la mayoría de los casos, de la posición que los individuos ocupan frente a la propiedad de la tierra y en las relaciones de producción agraria.

El análisis de la estructura agraria guatemalteca, y de los conflictos campesinos que de ella se han derivado en los últimos años, debe ser una referencia obligatoria para todo aquel que desea conocer de cerca las agitaciones que han surgido y se han desarrollado en el medio rural a lo largo del período de junio de 1993 a junio de 1994. Además, estos conflictos no pueden desvicularse de las causas 
socioeconómicas y políticas que determinaron el aparecimiento y la perduracion hasta nuestros días del movimiento insurrecional campesino y la guerra de contrainsurgencia del Ejército. La crisis económica y el alto grado de agitación política en que se encuentra actualmente el país se derivan directamente del proceso de deterioro en que entró la dominación de los finqueros al elevarse el nivel de concientización del campesinado. Pese a la brutal represión del Ejército en el medio rural, los largos años de insurgencia campesina han debilitado grandemente el tradicional poder local de los finqueros. Este se ve ahora más amenazado que nunca debido al surgimiento del nacionalismo indígena, al rebrote de las organizaciones campesinas como el CUC, a la formación en los diversos poblados de comités cívicos con fines electorales, y a las presiones de las organizaciones populares para una profunda revisión y modernizacion de la Constitución de la República.

Examinando con más detalle el acontecer en el medio rural guatemalteco, los datos que poseemos indican que con la nueva situación política creada a raíz del derrocamiento de Jorge Serrano Elías no se produjeron en dicho medio modificaciones sustanciales. De León Carpio adoptó algunas medidas encaminadas a reforzar su posición personal como nuevo mandatario del país, destituyendo a los gobernadores departamentales que habían sido nombrados por el depuesto Presidente Serrano, y asignando a personas de su confianza. Algunos otros cambios menores, así como información acerca de la adopción de otras medidas de gobierno, pueden seguirse a través de la prensa guatemalteca. Así, por ejemplo, el pasado 25 de marzo el diario Siglo XXI informaba que poco después de su ascenso al poder, los representantes de las 500 familias campesinas asentadas en la finca "Cajolá" le solicitaron audiencia al nuevo Presidente, para informarle que carecían de todo tipo de recursos para poder subsistir. Según ellos, el Gobierno se comprometió por escrito a construirles viviendas y escuela para educar a sus hijos, a otorgarles créditos para poder emprender sus cultivos, y a abrir vías de acceso a la finca. A fines de marzo de 1994 el Gobierno no había cumplido aún dicha promesa, creándose un conflicto potencial, ya que un vocero de los campesinos expres6 que "la comunidad quiere dialogar, pero si no se nos atiende, emprenderemos medidas de hecho, por lo que responsabilizamos desde ya al Gobier- 
no de lo que pueda ocurrir en un plazo de 15 dias". ${ }^{2}$

El Presidente De León Carpio, como si se encontrara en plena campaña eloctoral, ha procurado intervenir personalmente en la solución de los conflictos campesinos, mediando en las negociaciones entre finqueros y campesinos. Con ésto busca, por una parte, dar la impresión de que su gobierno no utiliza métodos represivos para disuadir al campesinado que exije que les resuelvan favorablemente sus problemas. Por otra parte, De León Carpio procura influir decisivamente en la desactivación de los conflictos sociales, ya que ésto es de gran importancia para la estabilidad del régimen y para mejorar la deteriorada imagen internacional del Estado guatemalteco. El Presidente De León pretende convencer a la opinión pública de que es capaz de tomar medidas acorde con las necesidades económicas y sociales de los sectores populares, pero la falta de un programa de gobierno que promueva e impulse cambios estructurales en el país impide la realización de cualquier proyecto renovador. Sus asesores civiles, pertenecientes casi todos a la intelectualidad pequeñoburguesa deseosa de escalar posiciones de poder dentro del aparato estatal, no escatiman esfuerzos para resolver los problemas más agudos y complicados del Gobierno. Sin embargo, tras bambalinas, los grandes propietarios y los defensores militares del orden establecido acentúan su presión sobre el nuevo Gobiemo, así como el control de la población campesina, empleando los métodos tradicionales de chantaje político, en el primer caso, y la violencia y el terror, en el segundo caso. El auge de los movimientos de masas urbanas y campesinas, no obstante, demuestran que en el país se está dando una situación política coyuntural, que permite, por primera vez en muchos años, reducir el poder absoluto del Jefe de Estado y de sus tradicionales aliados, los poderes Legislativo y Judicial.

En su afán por engañar a la opinión pública nacional e internacional y como parte de su campaña de diversionismo ideológico, el Gobierno pretende dar la imagen de que en Guatemala existe un Estado de derecho y se abre paso la democracia. Para tal fin los órganos represivos tradicionales toleran la existencia de algunos intelectuales regresados del exilio y de algunos otros de conocida trayectoria progresista que nunca han salido del país, quienes suelen escribir en la prensa análisis políticos y económicos con críticas 
al Gobierno. La realidad es que nuevamente se encuentran a la orden del día las trístemente celebres «listas negras» de condenados a muerte por "escuadrones de la muerte», elaboradas por los testaferros del sistema.

Como ya es tradicional en Guatemala, al desarrollo de los movimientos de masas se oponen las dos dificultades que desde hace decenas de años impiden la democratización del país: por un lado, la represión indiscrimnada de la población campesina por parte del Ejército; por otro, el sistemático asesinato y persecución de los dirigentes populares e intelectuales progresistas y revolucionarios por parte de las fuerzas de seguridad del Estado.

Guatemala es uno de los paises más atrasados en su desarrollo del Continente americano. Es un país donde predominan las grandes fincas dedicadas a la agro-exportacíón, al lado de la pequeña propiedad campesina en donde se generalmente cultivan granos básicos y que, dadas las difíciles condiciones de producción imperantes, ha mostrado ser insuficientes para producir los alimenbtos que necesita la población para su subsistencia.En Guatemala, desde siempre, la inmensa mayoría de la población ha vivido en el medio rural, en pequeñas aldeas que no sobrepasan los varios cientos de habitantes. Además, casi todas las ciudades están íntimamente vinculadas a la agricultura y se prolongan en el espacio hacia dicho medio rural, perdiendo muchas veces su carácter urbano dentro del perímetro mismo de la ciudad. La población agraria activa constituye más de las dos terceras partes de la población activa total, encontrándose la industria centralizada en la capital y el grueso del comercio en esta gran ciudad y en otras pocas ciudades del interior cercanas a los centros productores de café y caña de azúcar.

La estructura de la propiedad de la tierra acusa fuerte desequilibrio en todas las regiones, especialmente en el centro, suroccidente, y en el norte del país, donde imperan las grandes plantaciones de café, caña de azúcar y algodón, y las haciendas de ganado. El occidente y el oriente se caracterizan por ser zonas de 'minifundios en manos de campesinos indígenas dedicados a la producción de maíz y trigo, y de pequeños propietarios ladinos dedicados a la cría y engorde de ganado vacuno, aunque también pueden encontrarse grandes fincas y haciendas de ganado de pro- 
pietarios ausentistas. Las principales características de la estructura de la propiedad de la tierra pueden diferenciarse de la siguiente manera: Aunque no se conoce el porcentaje aproximado de la población activa agraria, puede asegurarse que la mayoría del campesinado no posee tierra de cultivo o posee en muy poca cantidad para poder vivir exclusivamente de su explotación, por lo que para poder subsistir tienen que estar atados a las fincas en calidad de colonos semiesclavos, aparceros o trabajadores agricolas. Las grandes plantaciones de café, caña de azúcar y algodón superiores a las 10 caballerías de terreno constituyen apenas el $5 \%$ de las explotaciones agrícolas, pero ocupan el $70 \%$ de las mejores tierras de cultivo, mientras que el $95 \%$ de las propiedades agrarias menores de 10 caballerías apenas ocupan el $30 \%$ de la superficie agraria del país. En base a este esquema puede asegurarse que en Guatemala predomina el latifundismo, pero es la pequeña propiedad la forma de organización agrícola más importante. Debido, sin embargo, a que la mayoría de las pequeñas propiedades tiene menos de 10 hectáreas, que es el número necesario para que una familia campesina que las cultiva pueda vivir decorosamente, encontramos que la mayor parte de los campesinos minifundistas viven en el marco de la pobreza. Por otra parte, la mayoría de los grandes finqueros son ausentistas, sólo cultivan una pequeña porción de sus latifundios, arrendan sus tierras o las tienen cedidas en aparcería. Una importante característica de la gran propiedad de la tierra, es que los grandes terratenientes no le pagan nada al fisco por tener sin cultivar grandes extensiones de sus propiedades. Otra, no menos importante, es que un número indeterminado de grandes propietarios son extranjeros que residen en la ciudad de Guatemala, en los EE.UU. o en sus países de origen si no son norteamericanos.

Las causas que han motivado los conflictos campesinos no son sólo la existencia de una obsoleta estructura de la propiedad de la tierra y la actitud intransigente y reacia a la modificación de esta estructura que han adoptado, desde siempre, los grandes terratenientes que controlan la Cámara del Agro. Entre estas causas se encuentran también las pésimas condiciones económicas en que sobrevive el campesinado guatemalteco, y el alto grado de explotación a que se encuentra someiido por parte de los finqueros. 
Estas son los motivos fundamentales que han determinado los conflictos políticos y sociales en que el campesinado guatemalteco se ha visto involucrado en el período comprendido entre el mes de junio de 1993 hasta el presente mes de julio de 1994, un año y un mes más tarde.

En ciertas ocasiones, los conflictos campesinos hay surgido por antiguos pleitos entre pequeños propietarios de tierras colindantes o entre individuos que se pelean por la posesión de una propiedad agraria. En otras ocasiones, han surgido conflictos campesinos cuando éstos, que suelen trabajar temporalmente en las fincas agroexportadoras, luchan por aumentos salariales. Los mayores enfrentamientos en el medio rural, sin embargo, han sido conflictos surgidos entre hombres sin tierras, que cansados de trabajar como asalariados rurales, han tomado la decisión de luchar por la adquisición de tierras de cultivo. En cualquier caso, en última instancia, ya sean conflictos originados por pleitos de tierras entre pequeños, medianos o grandes propietarios, conflictos entre los finqueros y sus trabajadores que exigen aumentos salariales, y conflictos surgidos por demandas de tierras de cultivo, se ha tratado de luchas provocadas por el choque de intereses económicos antagónicos.

A fin de defender sus intereses de clase, especialmente para preservar el status quo en el medio rural, luchar contra la reforma agraria, las reivindicacines campesinas de demanda de aumentos salariales, y el sindicalismo campesino, los grandes y medianos propietarios se han aglutinado y organizado en torno a diversas asociaciones agrarias y empresariales, especialmente en la Asociación General de Agricultores (AGA), Cámara del Agro y en el CACIF. Los tibios intentos gubernamentales de modificar la estructura de tenencia de la tierra, a fin de neutralizar cualquier movimiento agrarista surgido en el país, ha encontrado el rechazo absoluto de los grandes propietarios. Los voceros de éstos insisten en que la reforma agraria no es la solución para los problemas del agro, y abogan por cambios técnicos en los existentes sistema de producción agrícola (mejoras de las condiciones de los suelos, transformación del secano en regadío, alegando que el minifundio no es rentable, que no existen suficientes tierras para distribuir entre los campesinos, que los agraristas son enemigos de la propiedad 
privada, traidores a la patria, etc.

El sindicalismo en el medio rural guatemalteco es casi inexistente, aunque desde 1978 surgió el Comité de Unidad Campesina (CUC), con la finalidad de organizar al campesinado pobre para luchar por la tierra, aumentos salariales y otras reivindicaciones agrarias. En los últimos tiempos se ha formado la Central de Trabajadores del Campo (CTC), que se ha destacado por defender, sin mucho éxito, los derechos laborales y sindicales del campesinado. En unas pocas plantaciones de banano e ingenios de azúcar se han logrado formar sindicatos agrícolas, pese a que muchos de sus dirigentes han sido asesinados o expulsados por la fuerza de las plantaciones.

El campesinado organizado en el CUC, en su IV Asamblea Nacional realizada en 1993, acordaron, en el campo económico: a) luchar por "la solución democrática al problema de la tierra"; es decir, por la adquisición de tierras por medio de compras de fincas privadas, no excluyéndose la implementación de una reforma agraria; b) por un nuevo salario mínimo en las fincas; y c) «el desarrollo comunitario que permita fortalecer la lucha de la comunidad y el trabajo colectivo"; es decir, por la ampliación de las cooperativas de producción, por una favorable comercialización de los productos agrarios y artesanales campesinos y "contra el alza de los productos industriales que compramos para comer, vivir y trabajar". En el plano político y social, y a fin de dar término a la sistemática represión y militarización de que han sido objeto por parte del Ejército, los campesinos del CUC acordaron: a) luchar "por el respeto a los derechos humanos e indígenas de los trabajadores del campo, como la mejor forma de autodefensa civil de la comunidad"; y b) solidarizarse con los pueblos indígenas que luchan por el reconocimiento de sus identidades étnicas, su libertad ciudadana y la paz para Guatemala.

Debe mencionarse que existe una estrecha correlación entre las actuales condiciones de vida del campesinado y el potencial conflicto interétnico existente en las poblaciones rurales. Los estudios del sistema de propiedad de la tierra apenas se han ocupado de analizar las pequeñas propiedades de tipo familiar de los indígenas, que en el seno de sus regiones proporcionan un considerable 
equilibrio social interno. Estudiar este fenómeno es de especial importacncia y actualidad, porque está relacionado con el conocimiento de las características de las distintas conglomerados indígenas de la región de Los Altos, donde representantes de una burguesía indígena surgida de entre los comerciantes y terratenientes pugnan por sacar adelante un proyecto de nacionalismo nativo. No debe pasarse por alto que en Los Altos los grandes terratenientes no han constituído el sector dominante en la agricultura regional, por lo que los conflictos campesinos se han orientado hacia el rechazo del elemento foráneo, considerado desde siempre como intruso y avasallador en los medios rurales indígenas.

Los datos que permiten conocer la situación económica y el grado de pobreza en la que se desarrolla la precaria existencia de los pequeños propietarios indígenas de Los Altos, y su comparación con las condiciones de vida y miseria de los colonos, aparceros y trabajadores rurales ladinos, serán muy útiles para llegar a la conclusión de que el problema socioeconómico y político del campesinado guatemalteco no tiene causas de índole racial. Esta interpretación sólo resulta muy útil para los ideólogos de la guerra de contrainsurgencia, como parte de su campaña por desnaturalizar el contenido revolucionario de la insurgencia campesina. Desde el punto de vista de dichos ideólogos, resulta muy útil canalizar el descontento indígena y su odio al sistema de dominación de los terratenientes, hacia el rechazo de la injusta descriminación de que los indígenas han sido objeto por parte de los ladinos en general. Las condiciones de confusión ideológica imperantes en la sociedad guatemalteca, han permitido que la lucha de clases se presente como una lucha de razas antagónicas, así como el surgimiento de dirigentes indígenas que se han dedicado a encubrir su tarea contrarrevolucionaria y divisionistas con prédicas de un retorno a supuestas tradiciones culturales y de organización social "mayas", que facilitan la labor contrainsurgente del Ejército. Esto pone de manifiesto que los conflictos campesinos, sugidos como respuesta a las condiciones de explotación en las fincas y a la desigual distribución de la propiedad agraria, pueden ser canalizados a conflictos racistas que hacen perder la búsqueda de solución a los mencionados choques de intereses de clase.

El programa de luchas y reivindicaciones que los dirigentes del 
CUC presentaron en su IV Asamblea de 1993 presenta innovaciones respecto a sus orientaciones del período 1978-1993 sobre el tema de la reforma agraria. Esto pone de manifiesto de que pese a la represión y persecución de que ha sido objeto la organización campesina, aún está en capacidad de expresar su protesta ante la eliminación de la agenda que la cuestión agraria ha sufrido con los gobernantes de turno. Los dirigentes del CUC, conscientes del retroceso que ha sufrido el debate de la injusta estructura de la propiedad rural, han colocado como primer punto de su temario la lucha por la solución democrática al problema de la tierra. El rechazo de los empresarios agrarios y del Gobiemo a llegar a un acuerdo con el campesinado sobre este punto, indica que no aún no consideran que los conflictos sociales existentes en el país tengan como causa directa la desigual distribución de la riqueza. Pretenden que el desorden social imperante, la guerra insurgente campesina desatada desde hace más de treinta años, y la violencia rural terminarán el día en que el país se firme un Tratado de Paz entre los dirigentes guerrilleros y el Gobierno guatemalteco.

No quieren comprender que el panorama general de enfrentamiento reinante en las zonas rurales sólo puede cambiar para peor si no se toman medidas encaminadas a paliar la permanente hostilidad entre las clases sociales. De hecho, ningún Tratado de Paz puede eliminar la amenaza de que Guatemala entre en la oleada de violencia más dura de su historia si no se programa e implementa una reforma agraria democrática en el país. La ceguera de la clase dominante y del Gobiemo harán crecer el número y tipo de conflictos sociales que han existido hasta ahora. Aumentarán las ocupaciones campesinas de fincas, se alterará aún más el orden en el medio rural y proliferán los enfrentamientos armados entre campesinos y las fuerzas represivas, continuará la roturación ilegal de tierras en zonas protegidas del Petén, se incrementarán la delincuencia común, con su secuela de robos, secuestros y agresiones físicas a los finqueros y sus familiares, y la situación de crispación y tensión en la sociedad no podrán ser resueltos con la violencia y el terior del Estado, como ha ocurrido hasta hoy en día. La precaria estabilidad del orden establecido se ve fuertemente amenazado por el estallido de una guerra civil de impredecibles consecuencias.

Las causas que originaron estos conflictos y "qué sucedió des- 
pués", lo cual sólo es posible si se logra penetrar en las características del fenómeno de la crisis agraria y la violencia rural que azota a Guatemala desde hace cuatro décadas.

Por consiguiente, un examen más detenido de algunos de los conflictos antes expuestos nos permitirá conocer más de cerca la realidad social guatemalteca y la gran importancia que tiene en el país la solución del problema agrario. El conflicto campesino más reciente y que está aún sin resolver por las autoridades, es el surgido en la finca "Olga María", localizada en el municipio de Tiquisate, Departamento de Escuintla. El 20 de abril pasado, la Policía Nacional desalojó brutalmente de esta finca a más de 1,500 personas que conforman 300 familias campesinas, cuyos fundadores se establecieron en el lugar en el período de 1930 a 1944, aprovechando que se trataba de terrenos baldíos sin cultivar. Se trata de un área de aproximadamente 950 hectáreas, que los campesinos han trabajado ya por tres generaciones. El conflicto, de hecho, se inició hace 30 años, cuando se trató de desalojarlos de las tierras que habían roturado y puesto bajo cultivo, debido a que altos funcionarios de la época fueron sobornados por una empresa agrícola propiedad de extranjeros que codiciaba dichas tierras. Este desalojo se produjo, finalmente, en el período de 1966 a 1970, durante el gobierno corrupto de Julio César Méndez Montenegro.

Como consecuencia, un individuo de origen español convirtió los terrenos estatales en la finca "Olga María". En febrero de 1991, menos de un mes después de ascender al poder Jorge Serrano Elías, los campesinos desplazados ocuparon la finca, por considerar ilícita la propiedad del español, siendo expulsados con lujo de fuerza por la policía poco tiempo después. En febrero de este año los campesinos volvieron a ocupar la finca "Olga María", siendo nuevamente expulsados el 20 de abril por la Policía Nacional, después de un brutal ataque. La importancia de este conflicto campesino estriba en que plantea de la manera más brutal la necesidad de una revisión general de la estructura de la tenencia de la tierra en el país. Este conflicto, además de colocar sobre el tapete el problema de la injusta como desigual distribución de la tierra en Guatemala, sirve para mostrar una sociedad sumergida en una profunda crisis económica y social, con un campesinado tan combativo como en la miseria, al que le han sido arrebatados sus tierras de cultivo y ha sido marginado por los 
políticos corruptos y los inescrupulosos empresarios agrícolas.

El conflicto agrario que condujo al desalojo de los campesinos de la finca "Olga María" puso una vez más en evidencia el contubernio que existe entre las diversas instituciones estatales y los círculos gubernativos al servicio exclusivo de los finqueros. La expulsión de los campesinos fue legalizada después que la Corte de Constitucionalidad revocó el amparo provisional que en febrero les había otorgado la Sala Duodécima de la Corte de Apelaciones. La expulsión se llevó a cabo a raíz de una apelación interpuesta ante la Corte de Constitucionalidad por los abogados del finquero español. La violenta acción de la policía fue efectuada ante el juez de Paz de Tiquisate y delegados de la Procuraduría de los Derechos Humanos y del Ministerio Público, quienes la sancionaron con su presencia. No sin aprensión escribía un órgano de prensa que ya en el transcurso de 1994 se han producido otras "invasiones de tierras" en el país. Estos conflictos campesinos han hecho afirmar al ministro del Interior que "no se permitirán nuevas acciones de esta naturaleza", especialmente por ser "propiciadas por personas interesadas en manipular a los campesinos para causarle problemas al Gobierno".

Al estudiarse sistemáticamente el fenómeno de las ocupaciones de tierras por parte de los campesinos, se puede constatar que estos conflictos son provocados por la falta de tierras de cultivo y por el escaso interés de los diversos gobiernos en responder favorablemente a las demandas reivindicativas del campesinado. Estas demandas no han sido hechas sólo por los campesinos insurgentes revolucionarios, sino también, de manera pacífica, por el campesinado pobre que se organizó en torno a los comités pro-tierras que proliferaron en el país a raíz del movimiento agrarista encabezado por el padre Andrés Girón, en la primera mitad de 1986. De hecho, la ocupación de fincas de particulares y de tierras estatales dió inicio desde el momento en que el gobierno de Vinicio Cerezo se dedicó a embaucar a los campesinos, mediante ofrecimientos que no serían cumplidos de compras de fincas privadas e interminables negociaciones para la creación de comités pro-adquisición de tierras locales, que sólo buscaban arrebatarle al padre Andrés el protagonismo como líder agrarista, dividir su creciente movimiento reivindicativo, y corromper a los dirigentes campesinos que se ponian al servicio del partido Democracia Cristiana. Debido a 
que a los campesinos sólo se les entregó unas pocas fincas para que las cultivaran en el peor de los desórdenes y sin ningún tipo de ayuda financiera, muchos de ellos vieron agotada la vía conciliatoria para la adquisición de tierras, optando por la ocupación directa de fincas privadas. Estas acciones fueron respondidas con la brutalidad policial y la rotunda negativa de los finqueros a dialogar con los campesinos ocupantes y a debatir el tema de la redistribución de tierras entre el campesinado pobre. La intransigencia de los finqueros y la miseria y desesperación de los campesinos condujo a la polarización de las dos posiciones en pugna. La intervención del Estado no ha sido como mediador del conflicto agrario, sino como órgano represor al servicio de los grandes terratenientes. Esto hizo aumentar cada vez más la tensión y la violencia en el medio rural, no habiéndose podido llegar hasta hoy a ningún tipo de acuerdo favorable a los intereses de los campesinos.

Una característica de los conflictos campesinos de ocupación de tierras, es que han sido acciones aisladas y de carácter local. En todos los casos, las ocupaciones de fincas y los incidentes que las han acompañado se han producido después de que los finqueros no han querido discutir ni aceptar las demandas campesinas. Todo parece indicar que no ha habido ninguna organización que haya planificado ni coordinado las acciones de ocupación de los agraristas. Los débiles contactos que los campesinos tienen entre sí en las diferentes regiones del país y la secretividad con que los campesinos han preparado y llevado a cabo tales acciones ha actuado en contra de una movilización generalizada y solidaria. Además, si las acciones de ocupación de tierras hubieran sido planificadas por elementos políticos opositores al Gobierno, es muy posible que hubieran estado unida de alguna manera vinculadas al movimiento de insurgencia revolucionaria, lo cual no consta en ninguna parte. A pesar de estas circunstancias, la brutalidad de las fuerzas policiales contra los campesinos sólo ha sido igualado por la agresividad verbal de los finqueros contra las acciones de los agraristas. Siguiendo el discurso ideológico fascista que caracteriza a los terratenientes, los dirigentes campesinos han sido tildados de «líderes perversos" asesorados por marxistas. Según un vocero de los finqueros, las ocupaciones de tierra han obra de "instigadores 
profesionales, enemigos de la patria" "nacionales y extranjeros", que con sus "aviesos fines políticos", se han dado a la tarea de "convencer y empujar a grupos de campesinos inocentes, a veces, y a veces politizados, para invadir terrenos de propiedad privada, sin importales los daños que causan en tales propiedades, y conscientes del daño económico y social que causan a la Nación al desalentar cualquier inversión nacional o extranjera en el área rural de Guatemala".

Resulta muy significativo que se declaren falacias como la que entre los "asesores marxistas" de los campesinos se encuentran "gente rubia, a veces españoles, europeos y hasta americanos", y se profieran veladas amenazas como "ya sabemos qué organización clandestina está manejando todo ésto". El cinismo de los finqueros se pone de manifiesto, cuando, al rechazar el derecho de los campesinos de la finca "Olga María" a la propiedad de la tierra que han cultivado por tres generaciones, invocan precísamente el artículo 256 del Código Penal guatemalteco, que tipifica como delito de usurpación, con pena de cárcel de hasta tres años, a todo aquel que - tal y como el español que ha utilizado a la Policía Nacional para expulsar a los campesinos de su posesión-, "mediante violencia, engaño, abuso de confianza o clandestinamente, con fines de apoderamiento o aprovechamiento ilícito, despojare o pretendiere despojar a otro de la posesión o tenencia de un bien inmueble o de un derecho real constituido sobre el mismo, ya sea invadiendo el inmueble, manteniéndose en él o expulsando a sus ocupantes". Según quienes abogan por el derecho de propiedad que tienen los finqueros, "la pobreza de los campesinos no se soluciona invadiendo tierras y desalojando de las mismas a sus legítimos propietarios. Se puede superar con mejores salarios que el sector agrícola está dispuesto a pagar, y dando mejores servicios a ellos por parte del Estado, que es su obligación, como escuelas y verdaderos centros de salud que efectivamente atiendan sus necesidades, pero jamás se va a superar su situación con anarquía, con desorden, con irrespeto de la ley, y violando los preceptos constitucionales que garantizan la propiedad privada y la seguridad de los bienes y de las personas". 3

Otras muestras de intransigencia de los finqueros están dadas por el hecho de que se niegan rotundamente a permitir la formación de sindicatos campesinos en el medio rural, despidiendo a los 
trabajadores agrícolas que piden esta reivindicación y haciendo eliminar físicamente a los organizadores y dirigentes sindicales. Además, suelen pagar jornales ínfimos, que se encuentran generalmente por debajo del salaro mínimo, a la vez que les exigen a sus trabajadores jornadas de trabajo de 10 y más horas diarias. En algunas regiones del país aún persisten las relaciones de producción semiesclavistas, tal y como hace cien años. Este es el caso, por ejemplo, de las fincas de café del municipio del Estor, Izabal, mientras que en todas partes puede encontrarse condiciones de trabajo semifeudales. En las fincas donde predominan las relaciones de producción capitalistas, es común que no se respeten las leyes que regulan el trabajo a destajo, las jornadas de trabajo, los salarios minimos para hombres, mujeres y niños, los días de asueto y fiestas reglamentarias, el derecho a educación y a atención médica por cuenta de los patronos, diversas prestaciones laborales, etc. Por si lo anterior fuera poco, en la mayoría de las fincas existen guardias armados y espias de los patrones, encargados de tener bajo un férreo control a los campesinos, así como de eliminar físicamente a todos aquellos que provoquen conflictos o se sospeche que tienen vínculos con el movimiento insurgente.

En Guatemala, desde siempre, la violencia ha acompañado a los conflictos campesinos. Como es sabido, como resultado del movimiento campesino insurgente, la guerra contrainsurgente iniciada en 1962 ha causado la muerte de casi 200,000 hombres, mujeres y niños, y la desaparición del mapa de más de 400 aldeas y caseríos campeinos. Como no existen datos suficientes para elaborar un detallado cuadro de las muertes violentas ocurridas en el país durante los diez meses que dura el gobierno de Ramito de León Carpio, aún no es posible determinar el número de personas muertes por participar en la guerra insurgente y contrainsurgente, en conflictos campesinos de ocupaciones de tierras, y en otros incidentes violentos de carácter social (crímenes comunes y pasionales, disputas y riñas familiares y de taberna, etc.). Sin embargo, conociendo los procedimientos seguidos por los finqueros y demás miembros de la clase dominante en Guatemala para resolver los conflictos sociales, y debido a que en el país se han agudizado las contradicciones de clase y empeorado las condiciones económicas de la población trabajadora, no es aventurado decir que no han 
estado inactivos ni el Ejército, ni las demás fuerzas represivas que tradicionalmente han asesinado a los elementos insurgentes, a los campesinos involucrados en conflictos agrarios, a los sindicalistas e intelectuales, y, en general, a todos los opositores al sistema político de dominación.

La información que brinda la prensa guatemalteca, casi sin excepción al servicio de los intereses de la clase dominante, no siempre da una idea ni siquiera aproximada de las dimensiones de los crímenes cometidos por los defensores del status quo. Lo que sí pone de manifiesto la prensa, es que el campesinado sin tierra acompaña cada vez más sus reivindicaciones con la acción directa. Especialmente frecuentes durante estos meses fueron las ocupaciones de fincas particulares y tierras estatales. No conocemos la totalidad de hectáreas ocupadas por los campesinos ni el número de éstos que habían intervenido en dichas acciones, pero sólo en la Costa Sur, en marzo de este año, el número de fincas ocupadas por los campesinos ascendía a catorce. Como siempre, los finqueros expropiados se valieron de los medios legales y del uso de la fuerza pública para desalojar e intentar expulsar a los campesinos de sus propiedades.

Las noticias sobre ocupaciones de tierras privadas e invasiones campesinas y roturaciones de tierras selváticas de áreas consideradas protegidas en El Petén son aún más confusas. El hecho de que la prensa haya informado reiteradamente de campesinos que han sido expulsados de tierras fronterizas consideradas guatemaltecas por militares beliceños que alegaban pertenecer al Estado de Belice es una prueba más de que los conflictos de tierras son cada vez más agudos y que necesitan ser resueltos por medio de una reforma agraria. Sea como fuere, lo que sí es un hecho, es que en todos los casos, la reinvindicación fundamental de los campesinos ha sido la tierra, y que la respuesta del Gobierno ha sido el desalojo por la fuerza, lo cual indica claramente que una gran parte del campesinado guatemalteco carece de lo más mínimo para poder satisfacer sus necesidades más vitales.

Resumiendo nuestro análisis de los conflictos campesinos durante los primeros diez meses que ha estado en el poder Ramiro de León Carpio, puede afirmarse que no se sabe si en las fincas tuvieron lugar huelgas de trabajadores agrícolas, como ocurrió en el período de 
su antecesor Serrano. La conflictividad social se manifestó fundamentalmente en la ocupación de tierras privadas y estatales. Que, a instancias de los finqueros, estas ocupaciones estuvieron acompañadas por la violencia causada por la represion gubernamental. Que, pese a la afirmación de los voceros del Ejército, sus acciones contrainsurgentes no lograron aplastar la insurreción campesina guerrillera en todas las zonas del país.

Por el contrario, el estallido del movimiento campesino guerrillero en Chiapas le dió más vigor y un nuevo carácter, un carácter internacional, a la lucha insurreccional guatemalteca, al ampliar el conflicto del campesinado que demanda tierra a ambos lados de la frontera guatemalteca con México. Bajo estas condiciones, es posible llegar a la conclusión final de que el conflicto campesino por tierras ha experimentado cambios sustanciales, debido a que los campesinos que demandan tierras se han radicalizado en sus posiciones, atreviéndose cada vez mas a ocuparlas sin precio aviso. Como resultado de ésto, pese al sistematico hostigamiento de la policía y a la brutal represión del Ejército contra el campesinado, el conflicto social se encuentra aún muy lejos de ser resuelto. En un país fundamentalmente agrario como Guatemala, donde una reforma agraria democrática se encuentra a la orden del día, la clase dominante ha cerrado filas en su oposición a una medida semejante, la crisis económica y la crispación social se vuelven cada vez más agudas, el Ejército no ceja un ápice en su empeño por aplastar por medio de la fuerza militar la oposición campesina armada al sistema de dominación neocolonial, en donde no cesa la movilización forzada de campesinos y su integración en las Patrullas Civiles, cada día que pasa aumenta el grado de polarización social, el nivel de conflictividad campesina no puede ser sino cada vez mayor. La trascendencia de la cuestión agraria debe llevar a sociólogos, historiadores, antropólogos, y demás científicos sociales, a un mayor estudio de los problemas estructurales que subyacen en el medio rural guatemalteco, a fin de contribuir con su trabajo científico en la búsqueda de soluciones satisfactorias a dichos problemas. Sólo de esta manera podrán cumplir su verdadera misión profesional e histórica.

Según el CUC, "los cambios los hacen las masas", y en Guatemala "los cambios" están íntimamente relacionados con la modifica- 
ción de la estructura de la tenencia de la tierra por medio de una reforma agraria. Sólo a través de una refoma agraria se podría eliminar la miseria campesina. De esta miseria campesina, sin embargo, depende la riqueza y el bienestar de los grandes terratenientes agroexportadores. Por consiguiente el crecimiento e influencia del CUC entre el campesinado, la concientización de éste, condujo al fortalecimiento y auge del movimiento guerrillero de principios de la década de 1980. Desgraciadamenmte, condujo así mismo a las brutales represiones de tierra arrasada que le sucedieron. El conflicto social, que derivó en una situación revolucinaria de insurgencia campesina generalizada y la contrainsurgencia del Ejército que arrazó con más de 400 aldeas, causó más de 100,000 asesinatos, provocó la emigración de más de 250,000 refugiados, y el desplazamiento en el interior del país de más de un millón de refugiados de origen camapesino, tuvo su origen en el malestar social provocado por la existencia de las grandes propiedades agrarias y la explotación campesina por parte de los finqueros. Curiosamente, la dirigencia del movimiento guerrillero no presentó ningún proyecto de reforma agraria que implicara un cambio en la estructura agraria del país, ni la manera como se pensaba realizar la expropiación de los grandes terratenientes y el reparo de la tierra entre el campesinado. Fue posiblemente ésto lo que determinó su estancamiento y retroceso como movimiento insurrecional de las masas campesinas.

\section{Notas}

1. En este estudio es necesario distinguir y precisar el verdadero significado de lo que son las invasiones y las ocupaciones de fincas, hechos que generalmente llaman a confusión. La invasión de una finca consiste en penetrar a una propiedad rural sin autorización del propietario, con el fin de apoderarse de frutos, leña, etc. Es considerado un acto delictivo, en cuanto que al ser clasificado como robo a la propiedad privada, es penado por las leyes vigentes. Las ocupaciones son acciones directas realizadas por los campesinos, generalmente en contra de los deseos de quien alega ser el propietario. Consisten en que los campesinos que se han apoderado de una o más fincas, permanecen en ellas hasta que son desalojados por las fuerzas públicas o se dedican a trabajarlas y administrarlas como propias. En un proceso de Reforma Agraria, las ocupaciones de fincas son efectuadas de manera oficial, al legitimarlas las leyes emitidas al efecto.

2. "Cajolá: Gobierno ha incumplido acuerdos". En Siglo XXI, 25.3.1994, pág.4

3. "La invasión de fincas y el Estado de Derecho". En Siglo XXI, 3 de mayo de 1994. 